\title{
Biomaterial Treatment
}

National Cancer Institute

\section{Source}

National Cancer Institute. Biomaterial Treatment. NCI Thesaurus. Code C43442.

The process by which a biomaterial is created (from source biomaterials). Treatments have an order and an action. (caMAGE) 